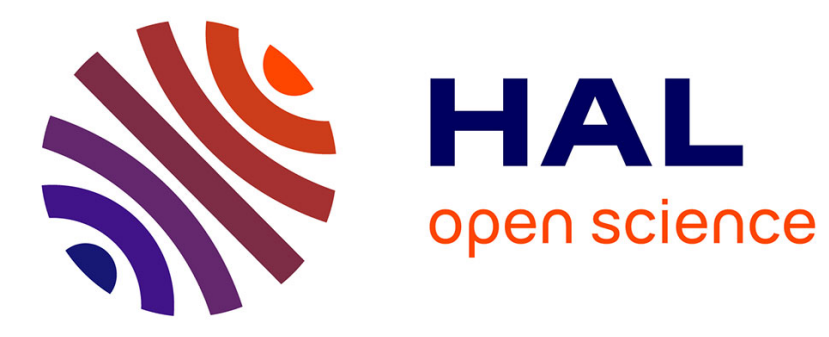

\title{
Near-surface dust flux enrichment in small particles during erosion events
}

Sylvain Dupont, S. Alfaro, G. Bergametti, B. Marticoréna

\section{To cite this version:}

Sylvain Dupont, S. Alfaro, G. Bergametti, B. Marticoréna. Near-surface dust flux enrichment in small particles during erosion events. Geophysical Research Letters, 2015, 42 (6), pp.1992-2000. 10.1002/2015GL063116 . hal-02324501

\section{HAL Id: hal-02324501 https://hal.science/hal-02324501}

Submitted on 21 Oct 2019

HAL is a multi-disciplinary open access archive for the deposit and dissemination of scientific research documents, whether they are published or not. The documents may come from teaching and research institutions in France or abroad, or from public or private research centers.
L'archive ouverte pluridisciplinaire HAL, est destinée au dépôt et à la diffusion de documents scientifiques de niveau recherche, publiés ou non, émanant des établissements d'enseignement et de recherche français ou étrangers, des laboratoires publics ou privés. 


\section{Geophysical Research Letters}

\section{RESEARCH LETTER \\ 10.1002/2015GL063116 \\ Key Points: \\ - The air gets saturated slower in small dust than in coarse dust \\ - Enrichment of dust flux in small dust with wind speed is possible \\ - Particle deposition velocity plays a crucial role in sorting dust particles}

\section{Supporting Information: \\ - Readme \\ - Movie S1}

\section{Correspondence to:}

S. Dupont,

sylvain.dupont@bordeaux.inra.fr

Citation:

Dupont, S., S. C. Alfaro, G. Bergametti, and B. Marticorena (2015), Near-surface dust flux enrichment in small particles during erosion events, Geophys. Res. Lett., 42, 1992-2000, doi:10.1002/2015GL063116.

Received 14 JAN 2015 Accepted 25 FEB 2015 Accepted article online 2 MAR 2015 Published online 19 MAR 2015

\section{Near-surface dust flux enrichment in small particles during erosion events}

\author{
S. Dupont ${ }^{1,2}$, S. C. Alfaro ${ }^{3}$, G. Bergametti ${ }^{3}$, and B. Marticorena ${ }^{3}$ \\ ${ }^{1}$ INRA, UMR 1391 ISPA, Villenave d'Ornon, France, ²Bordeaux Sciences Agro, UMR 1391 ISPA, Gradignan, France, \\ ${ }^{3}$ Laboratoire Interuniversitaire des Systèmes Atmosphériques, UMR CNRS 7583 Universités Paris Diderot and Paris Est, \\ Créteil, France
}

Abstract Mineral dust in the atmosphere impacts Earth's radiative budget and biogeochemical cycles. Sorting of dust-sized particles within the first few meters above the soil during wind erosion is still unknown. In particular, the sensitivity of the size distribution of dust flux to wind intensity has been questioned for years. This sensitivity is reanalyzed here using a novel erosion model developed in a turbulent airflow model. Starting from air free of dust, the suspension of small dust $(1.5 \mu \mathrm{m})$ needs several hours to reach a stationary state against about $20 \mathrm{~min}$ for coarser dust $(>5 \mu \mathrm{m})$. During this nonstationary phase, a continuous enrichment of the near-surface dust flux in small particles is simulated, enrichment enhanced with wind intensity. This is explained by the lower deposition velocity of small dust particles, a process usually ignored in interpretation of field data but that plays a crucial role in sorting dust particles.

\section{Introduction}

Mineral dust in the atmosphere affects the Earth's radiative budget by absorbing and diffusing solar and terrestrial radiation, and indirectly by impacting cloud and precipitation formation [e.g., Yin et al., 2002; Shao et al., 2011b]. Over a longer timescale, it also affects biogeochemical cycles by adding or removing nutrients to ecosystems [Mahowald, 2011]. Mineral dust contributes to a large uncertainty on the estimate of the impact of the total radiative forcing on the climate [Intergovernmental Panel on Climate Change, 2013], and existing global dust models still fail to predict accurately dust suspension [Uno et al., 2006; Todd et al., 2008; Huneeus et al., 2011; Evan et al., 2014]. Part of model discrepancies rely on the estimation of surface dust emission and deposition fluxes, and their size distribution, and chemical and mineral composition, both affecting dust optical properties [Textor et al., 2006; Knippertz and Todd, 2012].

The size distribution of dust emission fluxes and its dependence to wind condition remain controversial. On one hand, the wind tunnel experiments of Alfaro et al. $[1997,1998]$ showed that near-surface dust flux exhibits a significant enrichment in small dust particles with increasing wind speed. They explained it by the enhancement of soil particle disaggregation with wind speed as saltators have more energy to extract small particles. This led Alfaro and Gomes [2001] and Shao [2001, 2004] to propose dust emission models where the proportion of small particles in the dust emission flux increases with wind speed. This was recently supported by Sow et al. [2009] who observed a significant enrichment in small dust for the most energetic erosion events although no relationship between size distribution and fluctuations of the friction wind velocity was observed during erosion events. On the other hand, Kok [2011] argued that published measurements show no statistically significant trend with wind speed. He suggested that the disaggregation of soil under saltation has some similarity with the fragmentation of a brittle material and proposed for well-established erosion regimes, an analytical expression of the size distribution of dust fluxes depending on soil type but independent of the wind velocity. Kok explained this last assumption by the independence of the average saltator speed impacting the surface to the wind regime while the models of Alfaro et al. $[1997,1998]$ and Shao $[2001,2004]$ consider that saltator impact speed increases with increasing wind. Kok suggested that the size dependence of dust flux to wind speed observed by Alfaro et al. [1997] was due to the nonestablishment of the erosion regime. The approach of Kok [2011] is consistent with the model of Alfaro et al. [1997] provided that the speed of impacting saltators is effectively constant on average.

In this study, we reanalyze the dependence of the size distribution of the dust flux to the wind speed for erosion events starting from an air free of dust. To that purpose, we use the most detailed physically based soil erosion model to date to simulate at high-resolution dust emission, transport, and deposition over a 
bare soil for different wind conditions. The novelty of this model is to represent explicitly the main erosion processes (saltation, sandblasting, dust suspension) within a large eddy simulation airflow model that simulates instantaneous wind and thus turbulent flow eddies and erosion intermittency. This represents the first attempt to simulate the full erosion process in a turbulent flow.

\section{Model}

The three-dimensional saltation model of Dupont et al. [2013, 2014] is extended to dust suspension. All saltating and dust particles are considered spherical with a diameter $d_{p}$, a density $\rho_{p}$, and a mass $m_{p}\left(=\pi d_{p}^{3} \rho_{p} / 6\right)$.

\subsection{Saltation}

The sand bed is dry and composed of sand grains with various diameters that follow a multimodal size distribution. Under strong wind, the saltation of these grains is solved by modeling (1) individual particle trajectories through a Lagrangian particle motion equation, (2) the two-way interaction between the turbulent flow and particle motions, and (3) the surface splashing of particles, including rebound, ejection of other sand grains, or deposition. Interparticle collisions in the air and sand bed deformation are ignored. Particle aerodynamic entrainment is neglected as only well-developed saltation conditions are considered. Since only a statistically representative number of particle trajectories is explicitly resolved, a ratio $Q$ between the real number of particles and the number of numerically resolved particles is introduced in the wind flow conservation equations. Full details can be found in Dupont et al. [2013].

\subsection{Dust Dispersal}

As dust particles are smaller and more numerous than saltating particles, an Eulerian approach is preferred over a Lagrangian one to solve dust dispersal as it would be difficult to explicitly simulate the individual trajectory of a statistically representative number of dust particles. The size distribution of dust particles is divided into $n_{b}$ discrete bins characterized by a mean particle diameter $d_{p, b}$ and an interval $\Delta d_{p}$, where the subscript $b$ refers to the $b$ th bin. Hence, a separate and independent conservation equation of dust concentration $c_{b}$ is solved for each size bin (Einstein summation convention is used):

$$
\frac{\partial c_{b}}{\partial t}+\left(u_{i}-v_{s, b} \delta_{i 3}\right) \frac{\partial c_{b}}{\partial x_{i}}=-\frac{\partial \tau_{b, i}}{\partial x_{i}}
$$

where $t$ is time and $x_{i}\left(x_{1}=x, x_{2}=y\right.$, and $\left.x_{3}=z\right)$ refer to the streamwise, lateral, and vertical directions, respectively; $u_{i}\left(u_{1}=u, u_{2}=v, u_{3}=w\right)$ is the instantaneous velocity component along $x_{i}, \delta_{i j}$ is the Kronecker symbol, $v_{s, b}$ is the particle settling velocity $\left(=\rho_{p} g d_{p}^{2} C_{c} /(18 \rho v)\right.$ with $\rho$ the air density, $v$ the air molecular kinematic viscosity, $g$ the acceleration due to gravity, and $C_{c}$ the Cunningham correction factor), and $\tau_{b, i}$ the subgrid flux of dust. The latter flux is written as follows:

$$
\tau_{b, i}=-\frac{v_{t}}{P_{r}} \frac{\partial c_{b}}{\partial x_{i}}
$$

where $v_{t}$ is the eddy diffusivity and $P_{r}$ the Prandtl number. At the surface, this flux corresponds to dust released through sandblasting $\left(F_{s, b}\right)$ minus dust depositing on the surface $\left(F_{d, b}\right)$ :

$$
\left.\tau_{b, 3}\right|_{\text {surf }}=F_{s, b}-F_{d, b} \text {. }
$$

Unlike saltating particles, the impact of dust on the flow is neglected.

\subsection{Dust Emission and Deposition}

Using the same concept as the model of Alfaro and Gomes [2001], dust emission occurs only through the breakage of the cohesion forces of dust particles on soil sand grains by impaction of saltating particles (sandblasting). When a saltator $s$ impacts the surface, the kinetic energy available for releasing dust particles is

$$
\Delta E^{s}=\alpha\left(E_{\mathrm{imp}}^{s}-E_{\mathrm{reb}}^{s}-E_{\mathrm{ej}}^{s}\right),
$$

where $\alpha$ is the efficiency coefficient of energy transfer from the saltating to dust particles, $E_{\mathrm{imp}}^{s} E_{\mathrm{reb}}^{s}$ and $E_{\mathrm{ej}}^{s}$ are the kinetic energies of the impacting, rebounding, and ejecting saltating particles, respectively, which are explicitly simulated by the saltation model. 
As in Alfaro and Gomes [2001], dust particles released by sandblasting are sorted into three lognormally distributed modes independently of soil characteristics. The mass median particle diameter of these three modes are $1.5,6.7$, and $14.2 \mu \mathrm{m}$. Particles of the ith mode are characterized by a cohesion energy $e_{i}$ when aggregated to the soil. The number of dust particles released in bin $b$ by impacting saltators is the sum of dust particles released in each mode $i$ :

$$
F_{s, b}=\frac{Q}{\Delta x \Delta y \Delta t} \sum_{s=1}^{n_{s}} \sum_{i=1}^{3} \frac{p_{i} \Delta E^{s}}{e_{i}}\left(\frac{P_{i}\left(d_{p, b}\right) \Delta d_{p}}{\sum_{b=1}^{n_{b}} P_{i}\left(d_{p, b}\right) \Delta d_{p}}\right),
$$

where $\Delta t$ is the model time step, $\Delta x$ and $\Delta y$ are the grid cell sizes in the $x$ and $y$ directions, $n_{s}$ is the number of saltators impacting the area $\Delta x \Delta y$ per time step, $p_{i}$ is the fraction of the available kinetic energy $\left(\Delta E^{s}\right)$ used to release dust particles of mode $i$, and $P_{i}$ is the size distribution of released dust of mode $i$.

Dust deposition on soil occurs only through dry deposition accounting for gravitational settling, turbulent mixing, and Brownian diffusion, as usually done in large-scale models [e.g., Seinfeld and Pandis, 1998]. Hence, the deposition flux of dust particles from the $b$ th bin is

$$
F_{d, b}=v_{d, b} c_{b},
$$

where $v_{d, b}$ is the particle dry deposition velocity that is classically parameterized as a set of resistances [Wesely, 1989; Seinfeld and Pandis, 1998]:

$$
v_{d, b}=\left(r_{a}+r_{l, b}+r_{a} r_{I, b} v_{s, b}\right)^{-1}+v_{s, b}
$$

The aerodynamic resistance accounts for turbulent transfer near the surface: $r_{a}=\ln \left(z_{s} / z_{0}\right) /\left(\kappa u_{*}\right)$, where $z_{s}$ is the half height of the first grid cell above the surface, $z_{0}$ is the surface roughness length, and $u_{*}$ is the wind friction velocity near the surface $\left(u_{*}\right.$ was simply deduced here by assuming a logarithmic wind profile at $z_{s}$ ). The quasi-laminar resistance represents the transfer through a quasi-laminar layer adjacent to surface obstacles accounting for both the Brownian diffusion and the inertial impact of particles: $r_{l, b}=\left[u_{*}\left(S_{c}^{-2 / 3}+10^{-3 / S_{t}}\right)\right]^{-1}$, where $S_{c}=v / D_{g}$ is the Schmidt number (with the Brownian diffusivity $D_{g}=k T C_{c} /\left(3 \pi \rho v d_{p, b}\right), k$ is the Boltzmann's constant, and $T$ the air temperature) and $S_{t}=u_{*}^{2} v_{s, b} /(g v)$ is the Stokes number.

\subsection{Simulation Description}

Simulations of aeolian soil erosion were performed under idealized conditions: (1) a flat and infinite bare soil, (2) statistically constant wind events although turbulent eddies are explicitly simulated, (3) neutral atmosphere, meaning only shear-driven turbulence, and (4) air free of dust at the beginning of the event. Three wind conditions are investigated, characterized by friction velocities (with saltation) $u_{* s}$ of 0.47 , 0.63 , and $0.77 \mathrm{~m} \mathrm{~s}^{-1}$. Here $u_{* s}$ has been deduced from the momentum flux $\left\langle u^{\prime} w^{\prime}\right\rangle$ at $2 \mathrm{~m}$ height, where the symbol \langle\rangle denotes a time and horizontal space average and the prime denotes the deviation from the averaged value.

The soil and computational domain characteristics are similar to the ones used in Dupont et al. [2013] for which the saltation model has been evaluated successfully. The soil has a size distribution of sand grains with only one dominant population (one mode) characterized by a mass median particle diameter of $200 \mu \mathrm{m}$ and a geometric standard deviation of 1.2 , corresponding to a roughness length $z_{0}$ of $10 \mu \mathrm{m}$. The computational domain extends over $20 \times 15 \times 12 \mathrm{~m}$, corresponding to $200 \times 150 \times 100$ grid points in the $x, y$, and $z$ directions, respectively, and to a horizontal resolution $\Delta x$ and $\Delta y$ of $0.10 \mathrm{~m}$. The vertical grid resolution $\Delta z$ is $0.01 \mathrm{~m}$ at the surface, and the grid is stretched above. The lateral boundary conditions are periodic for both wind flow and particle motion, which simulates an infinite erodible soil. The bottom wind boundaries are treated as rigid and the surface momentum flux is parameterized by using bulk aerodynamic drag laws [Dupont and Brunet, 2008]. A $3 \mathrm{~m}$ deep Rayleigh damping layer is used at the upper boundary and the flow is driven by a depth-constant geostrophic wind corresponding to a base state wind at the upper boundary. Wind fields were initialized using a logarithmic profile. The flow, saltation particle motion and dust concentration equations were resolved with the same time step (0.0002 s). As in Dupont et al. [2013], simulations were performed in two steps. The flow dynamic was first solved without saltation and dust suspension. Once the flow dynamic reached an equilibrium state with the soil, then 10,000 initially resolved saltating particles were released randomly within the lower $0.3 \mathrm{~m}$ depth layer above the surface, and the 


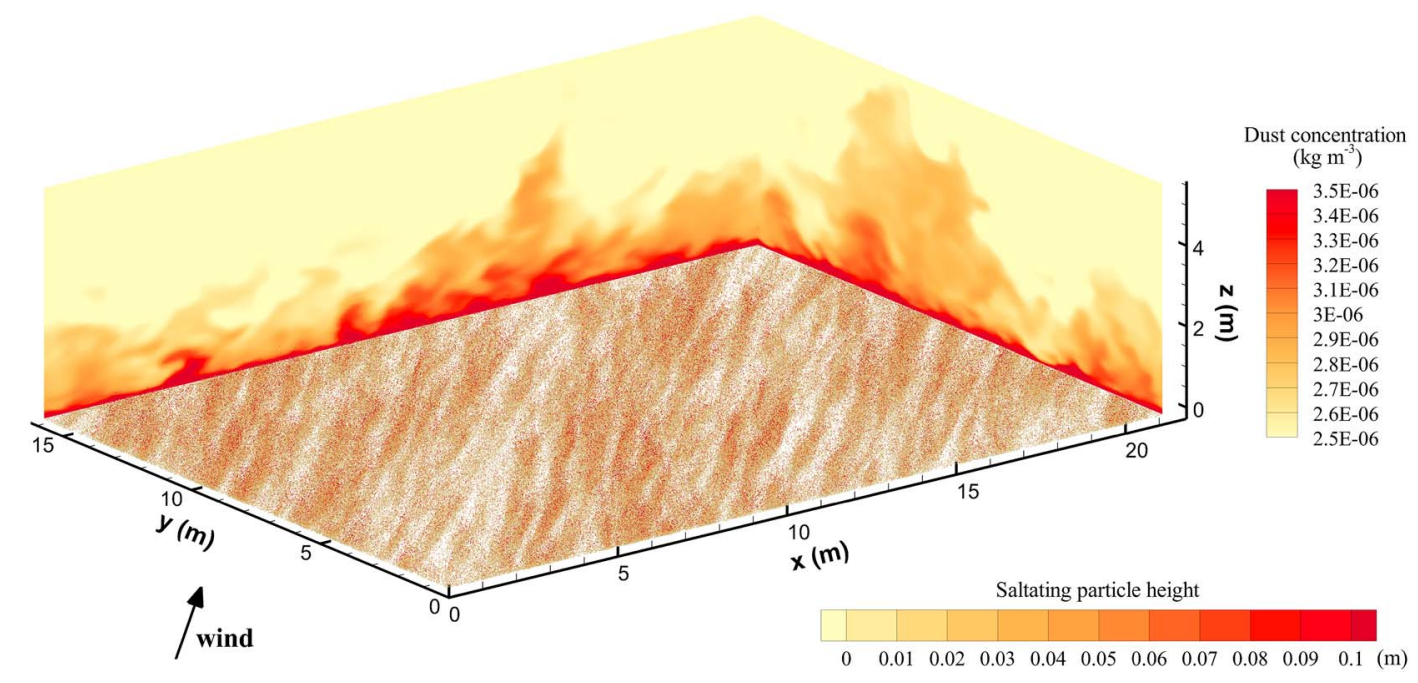

Figure 1. Snapshot of the aeolian soil erosion as simulated by the model $\left(u_{* s}=0.47 \mathrm{~m} \mathrm{~s}^{-1}\right)$ including saltation near the surface (each dot represents a numerically resolved sand particle, the color of dots informs on particle height) and dust suspension, visible from $1.5 \mu \mathrm{m}$ dust concentration in mass in $x-z$ and $y-z$ vertical sections.

erosion modules were activated. The diameter of these initial saltating particles was taken randomly from the size distribution of the soil grains. Erosion events of $20 \mathrm{~min}$ were simulated.

For this study, some simplifications in the dust emission scheme have been made: (1) the cohesion energy $e_{i}$ between dust particles and sand grains has been considered identical, independent of the dust particle size, (2) the fraction $p_{i}$ of the available kinetic energy used to release dust particles of mode $i$ has been chosen equal to $1 / 3$, meaning that particles of the three modes have the same probability of being released if the available kinetic energy is sufficient, and (3) the three modes of dust particles have a geometric standard deviation of 1 , meaning that all particles of modes 1,2 , and 3 have diameters of $1.5,6.7$, and $14.2 \mu \mathrm{m}$. This last simplification allowed us to consider only three bins, corresponding to the three modes of released dust particles. With these simplifications, the number of dust particles released in bin $b$ (or mode $i$ ) by impacting saltators (equation (5)) becomes

$$
F_{s, b}=\frac{Q}{\Delta x \Delta y \Delta t} \sum_{s=1}^{n_{s}} \frac{\Delta E^{s}}{3 e},
$$

where $e$ is the cohesion energy of dust, which controls the amplitude of dust emission. To obtain a sandblasting efficiency (ratio between dust and saltation fluxes) of the same order as reported in the literature [e.g., Gillette, 1979], e has been taken equal to $1.8 \times 10^{-9} \mathrm{~kg} \mathrm{~m}^{-2} \mathrm{~s}^{-2}$. Since only near-surface sorting of dust-sized particles other than the sandblasting one is investigated, a real size distribution and amplitude of emitted dust is unnecessary. The conclusions of this study are not expected to be sensitive to the value of $e$ as the dust emission is balanced by the dust deposition.

\section{Results}

To illustrate the model capability, Figure 1 shows an instantaneous view of the aeolian soil erosion as simulated by the model with (1) the saltation process near the surface, where each dot represents a sand particle, and with (2) the dust suspension process in vertical sections, where the dust concentration in air is solved. Blowing sand structures, known as aeolian streamers, are visible near the surface. These structures induce, by sandblasting, clouds of high dust concentration that disperse in the atmospheric surface layer through the flow turbulence (see the animation presented in the supporting information).

The time variation of the spatially averaged saltation flux, $G_{\text {tot }}$, shows that saltation reaches in less than $1 \mathrm{~min}$ a stationary state with fluctuations related to flow turbulence (Figures $2 \mathrm{a}$ and $2 \mathrm{~b}$ ), as observed in Dupont et al. [2013]. The time-averaged values of $G_{\text {tot }}$ as a function of $u_{* s}$ are consistent with values obtained in Dupont et al. [2013] (see Table 1). The spatially averaged dust emission flux, $F_{s, b}$, is equal in number (not in mass) for all particle diameters as specified in the emission model. As expected, $F_{s, b}$ behaves 

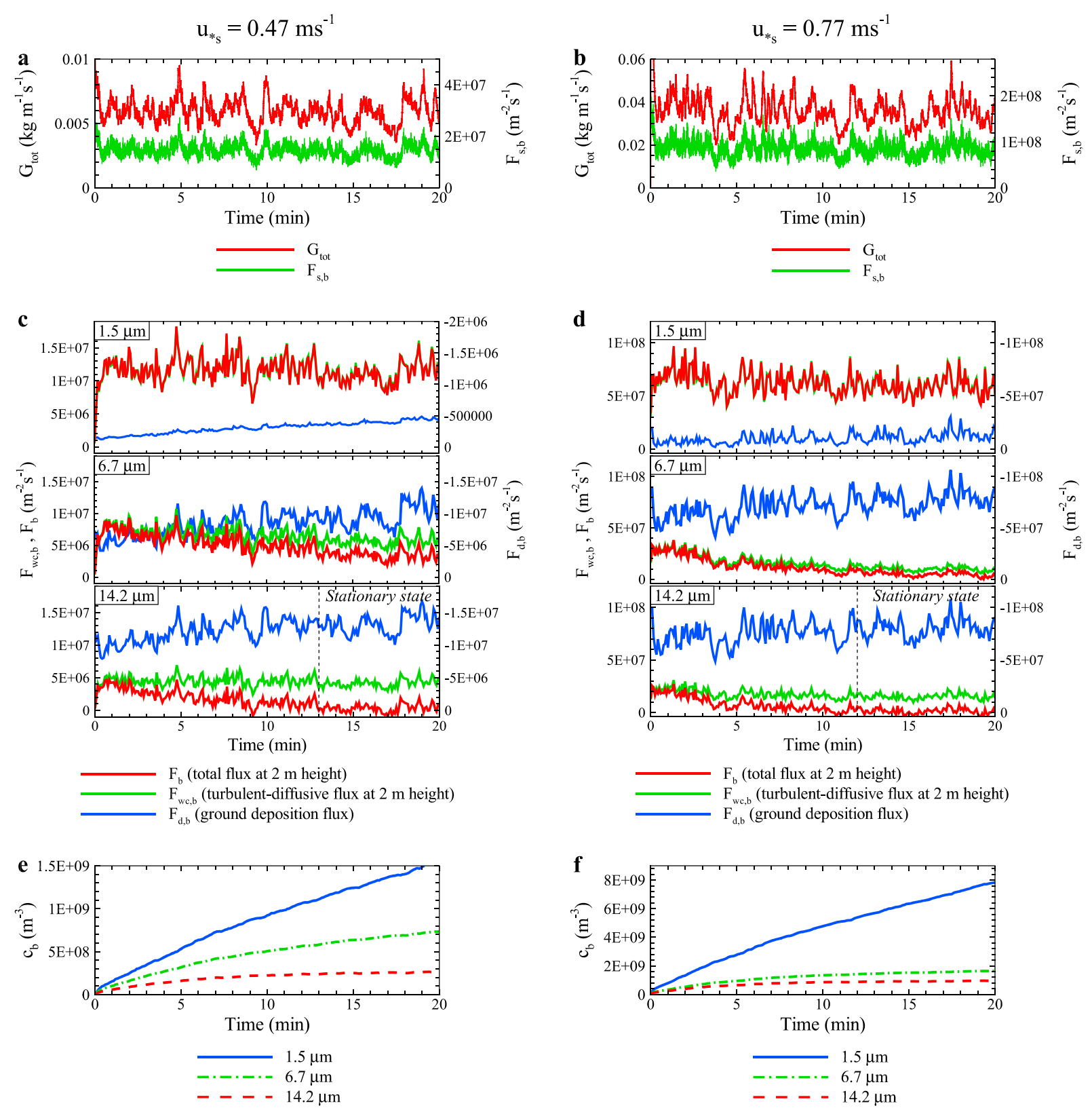

Figure 2. (a-b) Time variation of the spatially averaged saltation flux $G_{\text {tot }}$ and dust emission flux $F_{s, b}$, (c-d) dust deposition flux $F_{d, b}$, dust total flux at $2 \mathrm{~m}$ height $F_{b}$ and dust turbulent-diffusive flux at $2 \mathrm{~m}$ height $F_{\mathrm{wc}, b}$ of $1.5,6.7$, and $14.2 \mu \mathrm{m}$ dust, and (e-f) air concentration at $2 \mathrm{~m}$ height of the three dust sizes, for $u_{* s}=0.47 \mathrm{~m} \mathrm{~s}^{-1}$ (left side) and $0.77 \mathrm{~m} \mathrm{~s}^{-1}$ (right side). $G_{\text {tot }}$ has been evaluated from the spatially averaged instantaneous horizontal flux of saltating particles as done in Dupont et al. [2013]. The total dust flux includes the turbulent diffusive flux and the gravitational-settling flux, where $F_{\text {wc. } b}$ was deduced from correlations between the fluctuations of the vertical wind velocity component and the dust concentration. The vertical dashed lines in Figures $2 \mathrm{c}$ and $2 \mathrm{~d}$ indicate the transition between nonstationary and stationary states.

similarly as $G_{\text {tot }}$, reaching rapidly a stationary state as well (Figures $2 \mathrm{a}$ and $2 \mathrm{~b}$ ). On the other hand, the intensity of the spatially averaged dust deposition flux (in absolute value), $F_{d, b}$, is lower than $F_{s, b}$ (Figures $2 c$ and $2 d$ ) and increases continuously with time, with fluctuations in accordance with the saltation flux. As a consequence, the total dust flux at $2 \mathrm{~m}$ height $\left(F_{b}\right)$, including the turbulent diffusive flux due to turbulent motions $\left(F_{\mathrm{wc}, b}\right)$ and the gravitational-settling flux due to particle weight $\left(F_{\mathrm{set}, b}\right)$, decreases with time. The temporal trend of $F_{d, b}$, and thus $F_{b}$, is explained by the enhancement of the air dust concentration $\left(c_{b}\right)$ (Figures 2e and 2f), $F_{d, b}$ being proportional to $c_{b}$. Hence, unlike $G_{\text {tot }}$ and $F_{s, b}, F_{d, b}$ and near-surface dust fluxes reach a stationary state at a slower rate, more than $20 \mathrm{~min}$ for some particle diameters and wind conditions. 


\begin{tabular}{|c|c|c|c|c|c|c|c|}
\hline Cases & $\begin{array}{c}\overline{G_{\text {tot }}} \\
\left(\mathrm{kg} \mathrm{m}^{-1} \mathrm{~s}^{-1}\right)\end{array}$ & $T_{1}$ & $T_{2}$ & $T_{3}$ & $\begin{array}{c}v_{d, 1} \\
\left(\mathrm{~m} \mathrm{~s}^{-1}\right)\end{array}$ & $\begin{array}{c}v_{d, 2} \\
\left(\mathrm{~m} \mathrm{~s}^{-1}\right)\end{array}$ & $\begin{array}{c}v_{d, 3} \\
\left(\mathrm{~m} \mathrm{~s}^{-1}\right)\end{array}$ \\
\hline$u_{* s}=0.47 \mathrm{~m} \mathrm{~s}^{-1}$ & 0.006 & $15 \mathrm{~h}$ & $34 \mathrm{~min}$ & $13 \mathrm{~min}$ & $2.4 \times 10^{-4}$ & $2.7 \times 10^{-2}$ & $4.2 \times 10^{-2}$ \\
\hline$u_{* s}=0.63 \mathrm{~m} \mathrm{~s}^{-1}$ & 0.020 & $11 \mathrm{~h}$ & $25 \mathrm{~min}$ & $12 \mathrm{~min}$ & $2.6 \times 10^{-4}$ & $3.9 \times 10^{-2}$ & $5.2 \times 10^{-2}$ \\
\hline$u_{* s}=0.77 \mathrm{~m} \mathrm{~s}^{-1}$ & 0.036 & $4 \mathrm{~h}$ & $23 \mathrm{~min}$ & $12 \mathrm{~min}$ & $3.7 \times 10^{-4}$ & $4.8 \times 10^{-2}$ & $6.1 \times 10^{-2}$ \\
\hline
\end{tabular}

aSubscripts 1,2 and 3 refer to $1.5,6.7$, and $14.2 \mu \mathrm{m}$ dust, respectively.

This implies that the whole dust suspension process takes longer to reach a stationary state than the saltation process.

To evaluate the time $T_{b}$ needed for the air to reach a saturation state in dust diameter $d_{p, b}$, i.e., to reach an equilibrium state between emission and deposition, we extrapolated linearly the first 10 min trend of $F_{d, b}$ to find the time when $-F_{d, b}$ would be equal to $F_{s, b}$. Values of $T_{b}$ are reported in Table 1 . The nonstationary phase of the suspension process appears longer for small dust particles and for lower wind conditions. Saturation is reached in about $12 \mathrm{~min}$ for $14.2 \mu \mathrm{m}$ dust and $u_{* s}=0.77 \mathrm{~m} \mathrm{~s}^{-1}$, which is verified in Figure $2 \mathrm{~d}$ where $-F_{d, 3}$ is almost equal to $F_{s, 3}$ after $12 \mathrm{~min}, F_{3}$ is near zero, and in Figure $2 \mathrm{f}$ where $c_{3}$ becomes constant with time. On the other hand, for $1.5 \mu \mathrm{m}$ dust, several hours are needed to reach saturation in high wind conditions, to approximately $15 \mathrm{~h}$ for low wind conditions.

This long delay for dust to reach saturation has consequences on the size distribution of near-surface dust flux compared to the size distribution at emission. Figures $3 \mathrm{a}$ and $3 \mathrm{~b}$ present the time variation of the fraction of the turbulent-diffusive flux (solid lines) in number and in mass, respectively, of the three dust sizes to the total turbulent-diffusive dust flux $F_{\text {wc,tot }}$ at $2 \mathrm{~m}$ height, and for the three wind conditions. We recall that at the surface, these ratios have been imposed in the dust emission scheme to 0.33 (in number) for the three dust sizes, which corresponds in mass to $0.001,0.095$, and 0.904 for the $1.5,6.7$, and $14.2 \mu \mathrm{m}$ dust, respectively. At the beginning of the events, the fraction of $1.5 \mu \mathrm{m}$ dust in the dust flux is already
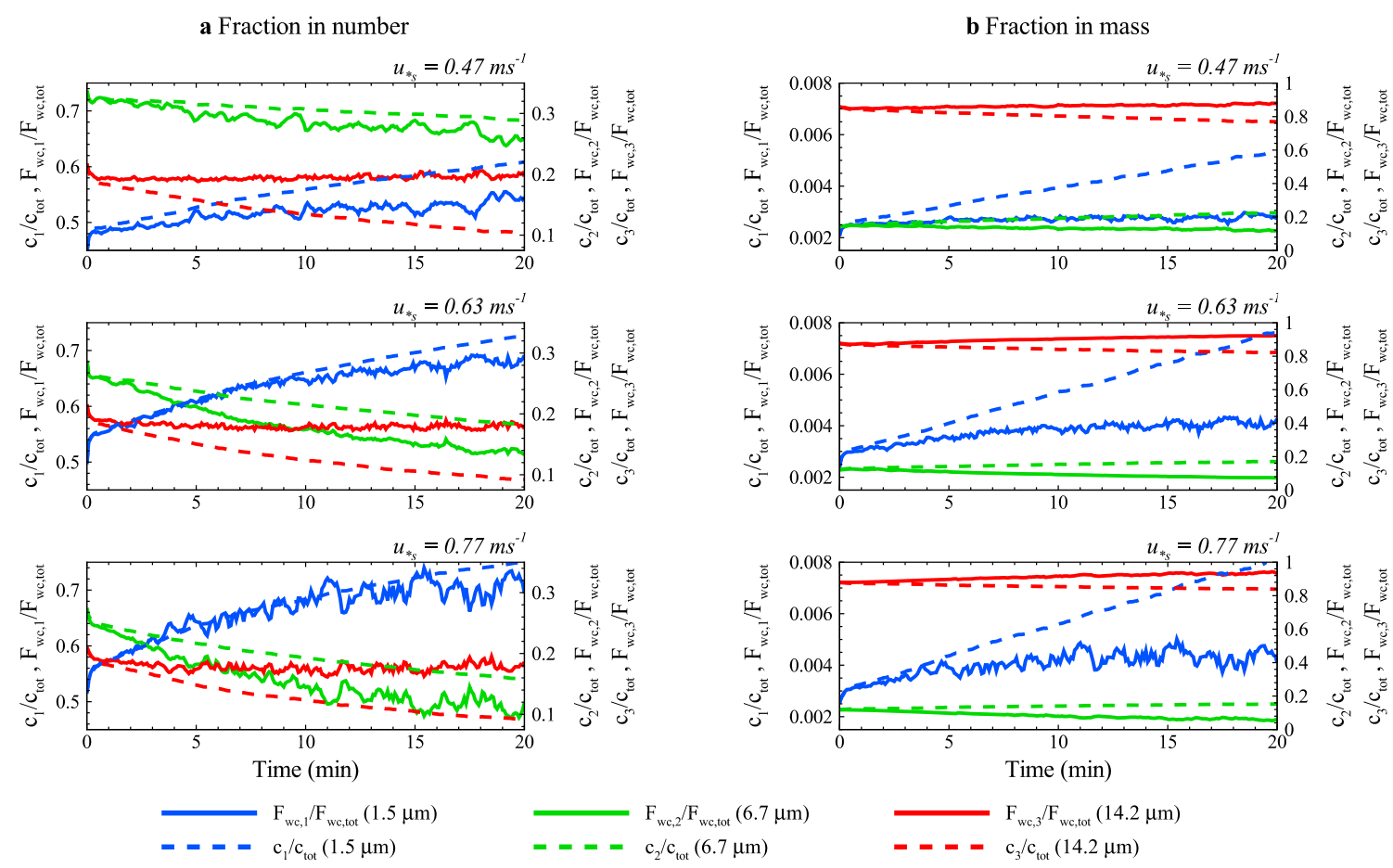

Figure 3. Time variation of the spatially averaged fraction (a) in number and (b) in mass of the three turbulent diffusive dust fluxes $F_{\mathrm{wc}, b}$ at $2 \mathrm{~m}$ height on the total turbulent diffusive flux $F_{\mathrm{wc} \text {,tot, }}$, and of the three dust particles concentration $c_{b}$ at $2 \mathrm{~m}$ height on the total concentration $c_{\text {tot }}$, for the three wind conditions ( $u_{* s}$ ). 
higher at $2 \mathrm{~m}$ than at emission due to the greater rate of deposition of the coarsest particles ( $14.3 \mu \mathrm{m})$ within the first meters above the soil. During the first $20 \mathrm{~min}$, the proportion in number of the $1.5 \mu \mathrm{m}$ dust flux increases while that of the $6.7 \mu \mathrm{m}$ particles decreases and that of the $14.3 \mu \mathrm{m}$ particles decreases during the first minutes before stabilizing. For the strongest event, the percentage of the $1.5 \mu \mathrm{m}$ dust flux goes from about $52 \%$ to $70 \%$ in 20 min while for 6.7 and $14.2 \mu \mathrm{m}$ dust fluxes it goes from $27 \%$ to $12 \%$ and $21 \%$ to $19 \%$, respectively, compared to the $33 \%$ at emission for the three particle diameters. This continuous enrichment in $1.5 \mu \mathrm{m}$ dust at $2 \mathrm{~m}$ height is due to the nonstationarity of the suspension process of small dust. This enrichment is greater during the first $10 \mathrm{~min}$ and greater with increasing wind speed. At $20 \mathrm{~min}$, $1.5 \mu \mathrm{m}$ dust flux represents $55 \%$ of dust particles for the lowest wind condition, and $70 \%$ for the highest wind condition. This enrichment of dust fluxes is also observed for dust concentrations with even larger amplitudes (dashed lines in Figures 3a and 3b). In terms of mass, the fraction of the $1.5 \mu \mathrm{m}$ dust is negligible, which leads for the strongest events (Figure $3 \mathrm{~b}$ for $u_{* s}=0.63$ and $0.77 \mathrm{~m} \mathrm{~s}^{-1}$ ) to an apparent stationary state after few minutes for 6.7 and $14.2 \mu$ m dust.

\section{Discussion}

A continuous enrichment of near-surface dust flux (turbulent diffusive flux within the first few meters) in small particles $(1.5 \mu \mathrm{m})$ is simulated during the nonstationary phase of the erosion development. This enrichment increases with wind speed. Since the size distribution of emitted dust was fixed, independently of the wind speed, this enrichment can only be explained by the particle deposition velocity $v_{d, b}$. Dust deposition of small particles $(1.5 \mu \mathrm{m})$ is much less than that of coarser dust $(6.7$ and $14.2 \mu \mathrm{m})$ as $v_{d, b}$ of small dust is always 2 orders of magnitude lower than that of coarser dust, around $10^{-4}$ and $10^{-2} \mathrm{~m} \mathrm{~s}^{-1}$, respectively (Table 1). Consequently, a high concentration of small dust particles (in number) in the air is required to reach saturation. This can take several hours depending on the wind speed, compared to about 20 min for coarser dust. With increasing wind speed, the higher enrichment of dust flux in small particles during the first 20 min of the erosion event is mainly explained by the more rapid unstationary phase, and less by $v_{d, b}$ as $v_{d, b}$ is approximately doubled for the three particle sizes when $u_{* s}$ increases from 0.47 to $0.77 \mathrm{~m} \mathrm{~s}^{-1}$. For stationary conditions, the possibility of dust flux enrichment in small particles with increasing wind speed remains unknown as these conditions have not been reached for small dust particles in our simulations.

The deposition velocity plays a major role in the variability of the size distribution of dust flux. Our understanding of the effect of this velocity with respect to particle size, wind condition, and surface characteristics is poor due to the difficulty of measuring it accurately. Existing parameterizations of $v_{d, b}$ exhibit a minimum value for the particle size range between 0.1 and $1 \mu \mathrm{m}$ [Petroff and Zhang, 2010]. Hence, particles within this range reach slower stationary condition than other particles, and enrichment of dust flux with this particle size should be expected during a nonstationary state. Here $v_{d, b}$ was computed from a standard parameterization used in large-scale dust models (section 2.3). The range of $v_{d, b}$ values simulated here and reported in Table 1 is consistent with existing data on bare soil. For example, Petroff and Zhang [2010] presented values around $1.5 \times 10^{-4}, 1.2 \times 10^{-2}$, and $5.0 \times 10^{-2} \mathrm{~m} \mathrm{~s}^{-1}$ for $1.5,6.7$, and $14.2 \mu \mathrm{m}$ dust, obtained from their model and compared with the experimental data of Sehmel [1973] for a smooth bare soil, with $u_{* s}=0.73 \mathrm{~m} \mathrm{~s}^{-1}$ and a particle density of $1500 \mathrm{~kg} \mathrm{~m}^{-3}$. More recently, Zhang et al. [2014] obtained from a wind tunnel experiment on a sand surface, values around $5 \times 10^{-3}, 3 \times 10^{-2}$, and $3 \times 10^{-2} \mathrm{~m} \mathrm{~s}^{-1}$ for $1.5,6.7$, and $14.2 \mu \mathrm{m}$ dust, $u_{* s}=0.49 \mathrm{~m} \mathrm{~s}^{-1}$, and a particle density of $2200 \mathrm{~kg} \mathrm{~m}^{-3}$. We are therefore confident with the order of magnitudes of deposition velocities simulated in this study and thus in the conclusions on the role played by the deposition velocity on the size distribution of dust fluxes.

The simulations reveal that the suspension process reaches a stationary state more rapidly with increasing wind speed, especially for small particles $(1.5 \mu \mathrm{m})$. Two reasons explain this feature. First, $v_{d, b}$ increases with wind speed, reducing the difference in magnitude between emission and deposition at the beginning of the event. Second, the concentration of saltating particles in air increases with increasing wind speed, which attenuates the turbulence within the saltation layer as compared to the one above (figure not shown), and thus reduces the transfer of dust particles from the saltation layer to the above atmosphere, and enhances dust deposition, especially for small dust. This second explanation results from the model hypothesis that saltating particles attenuate the flow turbulence due to their added drag on the flow [Dupont et al., 2013]. 
The long nonstationary state period of dust suspension means that for typical timescales of erosion events, small dust particles would unlikely reach a stationary state, as the suspension mechanism of such particles lasts more than few hours. On one hand, this duration may be underestimated in simulations due to the limited vertical size of the computation domain that restrains particle dispersal above $9 \mathrm{~m}$ height, especially for the smallest dust particles. On the other hand, this duration is accentuated here by the assumption that the air is free of dust at the beginning of the erosion event. This initial condition is representative of wind tunnel experiments. In field experiments, this is encountered downwind a long nonerosive area such as dense vegetated areas, on the coast, downwind seas, or for a wind event starting at the measurement location. In convective storms, this may be encountered before the dust front passage. However, during its passage, the advected air is probably already saturated in dust, limiting the nonstationary state of dust suspension.

The influence of $v_{d, b}$ on the enrichment of the near-surface dust flux in small dust particles may explain features previously observed in wind-tunnel experiments. In particular, the enrichment observed by Alfaro et al. [1997] with increasing wind may be partly or totally explained by the non-stationarity of the dust suspension process and by the variability of the deposition velocity with dust diameter and wind speed. A comparison between the predictions of the dust emission model of Alfaro and Gomes [2001], which was based on the wind tunnel experiment, and those of our model leads to the same level of enrichment: $+11.5 \%(+14.9 \%)$ in $1.5 \mu \mathrm{m}$ dust, $-10.8 \%(-13.8 \%)$ in $6.7 \mu \mathrm{m}$ dust, and $-0.7 \%(-1.1 \%)$ in $14.2 \mu \mathrm{m}$ dust, for $u_{* s}$ increasing from 0.47 to $0.77 \mathrm{~m} \mathrm{~s}^{-1}$, as predicted in number by the Alfaro and Gomes's' model (here at $20 \mathrm{~min})$.

In field experiments, the limited trend of size distribution of near-surface dust fluxes with wind speed, as reported by Kok [2011], could be explained (1) by the stationarity of the erosion events, assuming that the size distribution of emitted dust is independent of wind speed and also (2) by an inappropriate comparison of dust fluxes measured at different heights, obtained from different intensity and duration events, or processed with different time integrations. For example, in our simulations, the same size distribution of $2 \mathrm{~m}$ height dust fluxes could be obtained for two erosion events of different intensities by integrating dust fluxes over different time periods. Unlike wind conditions, the possibility of nonstationary state of dust suspension is usually not considered in measurement analysis while it can impact significantly the size distribution of dust flux, especially in wind tunnel experiments and lead to a nonconstant dust flux with height. This should be considered when interpreting and comparing dust fluxes from different events and measured at different heights.

Importantly, simulations show also that the size distribution and magnitude of dust fluxes measured at a few meters height differ from those of the emitted flux at the surface as particles start to be sorted through the deposition process within the saltation layer. Consequently, when evaluating or calibrating "physically based" dust emission schemes against measured near-surface turbulent diffusive dust fluxes, emission schemes should either account for this particle-sorting process between the surface and the measurement level, or they should be compared with measured dust flux that also accounts for gravitational settling. To date, most physically based dust emission schemes are erroneously directly evaluated against near-surface turbulent diffusive dust fluxes; only Shao et al. [2011a] applied a correction to measured dust flux to account for gravitational settling.

Finally, the possible dependency of the size distribution of emitted dust to the wind speed was ignored in this study. This point needs further research to be confirmed.

\section{Conclusion}

We demonstrated for the first time that in some conditions the suspension of small dust (around $1 \mu \mathrm{m}$ ) can be a long nonstationary process (several hours depending on the wind intensity) due to the low deposition velocity of this particle size range. This leads to a continuous enrichment of the near-surface dust flux in small particles, enrichment that is enhanced with wind intensity, independently of the possible role of saltators. These results emphasize the importance (1) of accounting for this nonstationary process when analyzing wind tunnel and field measurements, (2) of measuring dust fluxes per size class at high frequency to follow accurately their time variation, and (3) of better quantifying dust deposition velocity in field measurements. 


\section{Acknowledgments}

We would like to thank the Center for Analysis and Prediction of Storms (CAPS) at the University of Oklahoma for providing the ARPS code. Computer simulations related to this work were performed using the Avakas cluster from MésoCentre MCIA the ISPA cluster, and the Ada cluster at the Institut du Développement et des Ressources en Informatique Scientifique (IDRIS), Orsay, France (project IDRIS i2015017395). Thanks are expressed to Mark R. Irvine for his help with the ISPA cluster setup and administration. Financial supports from the Department 'Environnement et Agronomie' of INRA and of the French INSU/EC2CO program (MODUST and SalChiPhy-MODUST projects) are gratefully acknowledged. Numerical data used to produce Figures 2 and 3 are accessible through the author. Finally, we thank J.A. Gillies and two anonymous reviewers for their helpful comments.

The Editor thanks Jack Gillies and an anonymous reviewer for their assistance in evaluating this paper.

\section{References}

Alfaro, S., and L. Gomes (2001), Modeling mineral aerosol production by wind erosion: Emission intensities and aerosol size distributions in source areas, J. Geophys. Res., 106(D16), 18,075-18,084, doi:10.1029/2000JD900339.

Alfaro, S., A. Gaudichet, L. Gomes, and M. Maillé (1997), Modeling the size distribution of a soil aerosol produced by sandblasting, J. Geophys. Res., 102, 11,239-11,249.

Alfaro, S., A. Gaudichet, L. Gomes, and M. Maillé (1998), Mineral aerosol production by wind erosion: Aerosol particle sizes and binding energies, Geophys. Res. Lett., 25, 991-994.

Dupont, S., and Y. Brunet (2008), Influence of foliar density profile on canopy flow: A large-eddy simulation study, Agric. For. Meteorol., $148,976-990$.

Dupont, S., G. Bergametti, B. Marticorena, and S. Simoëns (2013), Modeling saltation intermittency, J. Geophys. Res. Atmos., 118, 7109-7128, doi:10.1002/jgrd.50528.

Dupont, S., G. Bergametti, and S. Simoëns (2014), Modeling aeolian erosion in presence of vegetation, J. Geophys. Res. Earth Surf., 119, 168-187, doi:10.1002/2013JF002875.

Evan, A., C. Flamant, S. Fiedler, and O. Doherty (2014), An analysis of aeolian dust in climate models, Geophys. Res. Lett., 41, 5996-6001, doi:10.1002/2014GL060545.

Gillette, D. A. (1979), Environmental factors affecting dust emission by wind erosion, in Saharan Dust, edited by C. Morales, pp. 71-94, John Wiley, New York.

Huneeus, N., et al. (2011), Global dust model intercomparison in AEROCOM Phase I, Atmos. Chem. Phys., 11(15), 7781-7816, doi:10.5194/acp-11-7781-2011.

Intergovernmental Panel on Climate Change (2013), Climate change 2013, in The Physical Science Basis. Contribution of Working Group I to the Fifth Assessment Report of the Intergovernmental Panel on Climate Change, edited by T. F. Stocker et al., 1535 pp., Cambridge Univ. Press, Cambridge, U. K., and New York.

Knippertz, P., and M. Todd (2012), Mineral dust aerosols over the sahara: Meteorological controls on emission and transport and implications for modeling, Rev. Geophys., 50, RG1007, doi:10.1029/2011RG000362.

Kok, J. F. (2011), Does the size distribution of mineral dust aerosols depend on the wind speed at emission?, Atmos. Chem. Phys., 11(19), 10,149-10,156, doi:10.5194/acp-11-10149-2011.

Mahowald, N. (2011), Aerosol indirect effect on biogeochemical cycles and climate, Science, 334(6057), 794-796, doi:10.1126/science.1207374

Petroff, A., and L. Zhang (2010), Development and validation of a size-resolved particle dry deposition scheme for application in aerosol transport models, Geosci. Model Dev., 3(2), 753-769, doi:10.5194/gmd-3-753-2010.

Sehmel, G. (1973), Particle eddy diffusivity and deposition velocities for isothermal flow and smooth surfaces, J. Aerosol Sci., 4, $125-138$. Seinfeld, J., and S. Pandis (1998), Atmospheric Chemistry and Physics, 1326 pp., John Wiley, New York.

Shao, Y. (2001), A model for mineral dust emission, J. Geophys. Res., 106(D17), 20,239-20,254, doi:10.1029/2001JD900171.

Shao, Y. (2004), Simplification of a dust emission scheme and comparison with data, J. Geophys. Res., 109, D10202, doi:10.1029/2003JD004372.

Shao, Y., M. Ishizuka, M. Mikami, and J. F. Leys (2011a), Parameterization of size-resolved dust emission and validation with measurements, J. Geophys. Res., 116, D08203, doi:10.1029/2010JD014527.

Shao, Y., K.-H. Wyrwoll, A. Chappell, J. Huang, Z. Lin, G. McTainsh, M. Mikami, T. Tanaka, X. Wang, and S. Yoon (2011b), Dust cycle: An emerging core theme in Earth system science, Aeolian Res., 2, 181-204.

Sow, M., S. C. Alfaro, J. L. Rajot, and B. Marticorena (2009), Size resolved dust emission fluxes measured in Niger during 3 dust storms of the AMMA experiment, Atmos. Chem. Phys., 9(12), 3881-3891.

Textor, C., et al. (2006), Analysis and quantification of the diversities of aerosol life cycles within AEROCOM, Atmos. Chem. Phys., 6, 1777-1813.

Todd, M. C., et al. (2008), Quantifying uncertainty in estimates of mineral dust flux: An intercomparison of model performance over the Bodele Depression, northern Chad, J. Geophys. Res., 113, D24107, doi:10.1029/2008JD010476.

Uno, l., et al. (2006), Dust model intercomparison (DMIP) study over Asia: Overview, J. Geophys. Res., 111, D12213, doi:10.1029/2005JD006575.

Wesely, M. (1989), Parameterizations of surface resistance to gaseous dry deposition in regional-scale numerical models, Atmos. Environ., 23, 1293-1304.

Yin, Y., S. Wurzler, Z. Levin, and T. G. Reisin (2002), Interactions of mineral dust particles and clouds: Effects on precipitation and cloud optical properties, J. Geophys. Res., 107(D23), 4724, doi:10.1029/2001JD001544.

Zhang, J., Y. Shao, and N. Huang (2014), Measurements of dust deposition velocity in a wind-tunnel experiment, Atmos. Chem. Phys. Discuss., 14, 9439-9474. 